\title{
Los hoteles de campo y el transporte de lana en la conformación del espacio rural del NO del Territorio Nacional de Santa Cruz (1880-1950) ${ }^{1}$
}

\section{Hotels and wool transportation in the conformation of the rural area of the NW of the National Territory of Santa Cruz (1880-1950)}

\author{
Martin Acuña Lugo, Silvana Espinosa, Viviana Navarro \\ acunamartinl@gmail.com,silvanaespinosa@conicet.gov.ar,vnavarro@uarg.unpa.edu.ar \\ Universidad Nacional de la Patagonia Austral - Unidad Académica Rio Gallegos \\ Av. Piloto "Lero" Rivera y Av. Gdor. Gregores - Río Gallegos, Santa Cruz. \\ CIT Santa Cruz CONICET UNPA UTN
}

Recibido: 22/05/2020. Aceptado: 17/11/2020

\section{RESUMEN}

El presente trabajo brinda un panorama acerca de los hoteles de campo y el transporte de la lana en la conformación del espacio rural del NO del Territorio Nacional de Santa Cruz (TNSC) entre los años 1880-1950. El análisis de la historia de los Hoteles "Riera", "Las Horquetas", "Olnie" y "Bajo Caracoles" -antiguos boliches de la región- resulta revelador de un mundo rural dinámico, con una intensa vida social, en una región que hasta ahora había sido caracterizada por la historiografía como un espacio despoblado y marginal a los grandes centros de actividad económica del TNSC.

Palabras clave: Hoteles; transporte de lana; espacio rural.

\begin{abstract}
This work provides an overview of country hotels and wool transportation in the conformation of the rural area of the NW of the National Territory of Santa Cruz (TNSC) since 1880 to 1950. The analysis of "Riera", "Las Horquetas", "Olnie" and "Bajo Caracoles" old hotels in the region- history is revealing of a dynamic rural world, with an intense social life, in a region that until now historiography had been characterized as an unoccupied and marginal space to the great centers of economic activity in the National Territory of Santa Cruz.
\end{abstract}

Keywords: Hotels; wool transportation; rural area.

\footnotetext{
${ }^{1}$ Los avances aquí presentados se corresponden con el plan de trabajo "Los paradores/hoteles de campo en la ruta de comercialización de la lana ovina (1880-1950) en el NO de Santa Cruz. Primer acercamiento y valoración de potencialidad turística" de la Beca de Estímulo a las Vocaciones Científicas del Consejo Interuniversitario Nacional (EVC-CIN). Este plan de trabajo se inserta en el proyecto de investigación (PI 29/A391-1) Corredor RN40 (Santa Cruz) “Análisis de la potencialidad turística y propuestas para planificar el desarrollo sustentable en el tramo Gobernador Gregores - Perito Moreno”, que busca ser una herramienta sistematizada de contribución a la gestión sostenible y responsable de las actividades turísticas, considerando a la Ruta Nacional No40 (RNN 40$)$ como eje articulador.
} 


\section{INTRODUCCIÓN}

El análisis de los hoteles de campo "Riera", "Las Horquetas", "Olnie" y "Bajo Caracoles" busca constituirse en material de base para el abordaje de las actividades turísticas de la región y contribuir al conocimiento de la historia rural de este sector del Territorio Nacional de Santa Cruz (TNSC), brindando información acerca de la vida social y económica de la región en el periodo 1880-1950. Para identificar el potencial turístico de los sitios se evalúa la diversidad y cantidad de recursos disponibles; se determina aquellos recursos aptos para el uso turístico, a fin de establecer acciones que mejoren su calidad y uso, detectando aquellos con potencialidad para integrar productos turísticos. La recopilación de información respecto de los elementos de uso turístico, finalmente, conforma una base de datos para el diseño de políticas, programas, proyectos y planes turísticos (Ferrari et al 2015).

La trayectoria histórica de los hoteles que se describirá fue realizada siguiendo como método de trabajo la investigación documental, indagando fuentes inéditas y directas -tales como los registros comerciales de los correspondientes locales y sus dueños- y fuentes secundarias y éditas -tales como algunos testimonios realizados por contemporáneos dedicados al seguimiento de la actividad económica del TNSC, fuentes periodísticas y obras de la historiografía regional.

Los resultados nos muestran un mundo rural dinámico, con una intensa vida social, en una región que hasta ahora había sido caracterizada por la historiografía como un espacio despoblado y marginal.

\section{Marco histórico}

\section{MARCO DE REFERENCIA}

El trabajo abarca el periodo correspondiente al proceso de colonización del espacio de la actual provincia de Santa Cruz impulsado por el gobierno nacional argentino (1884-1955). Este periodo se encuentra marcado -en el plano económico y social- por la transferencia efectiva de tierras consideradas fiscales a manos privadas ${ }^{2}$, con la respectiva consolidación de la propiedad privada capitalista y la extensión de la ganadería ovina en el territorio (Barbería, 1995). El periodo elegido se extiende más allá del momento de "auge ovino" (1880-1920), entendiendo que el proceso de colonización del territorio en el área de estudio será incipiente hacia mediados de la década de 1930 y que se consolidará de forma definitiva hacia la década de 1950.

\section{Ubicación espacial}

El área de estudio de este trabajo se circunscribe al NO de la actual provincia de Santa Cruz, más específicamente al tramo Gobernador Gregores - Perito Moreno de la actual Ruta Nacional N40 (Figura 1).

\footnotetext{
2 Estas tierras, correspondientes a la Patagonia Austral, se encontraban ocupadas por distintas poblaciones cazadoras-recolectoras, basadas en un amplio patrón de movilidad, de forma previa a la apropiación de estos espacios por parte del naciente Estado-Nación argentino.
} 


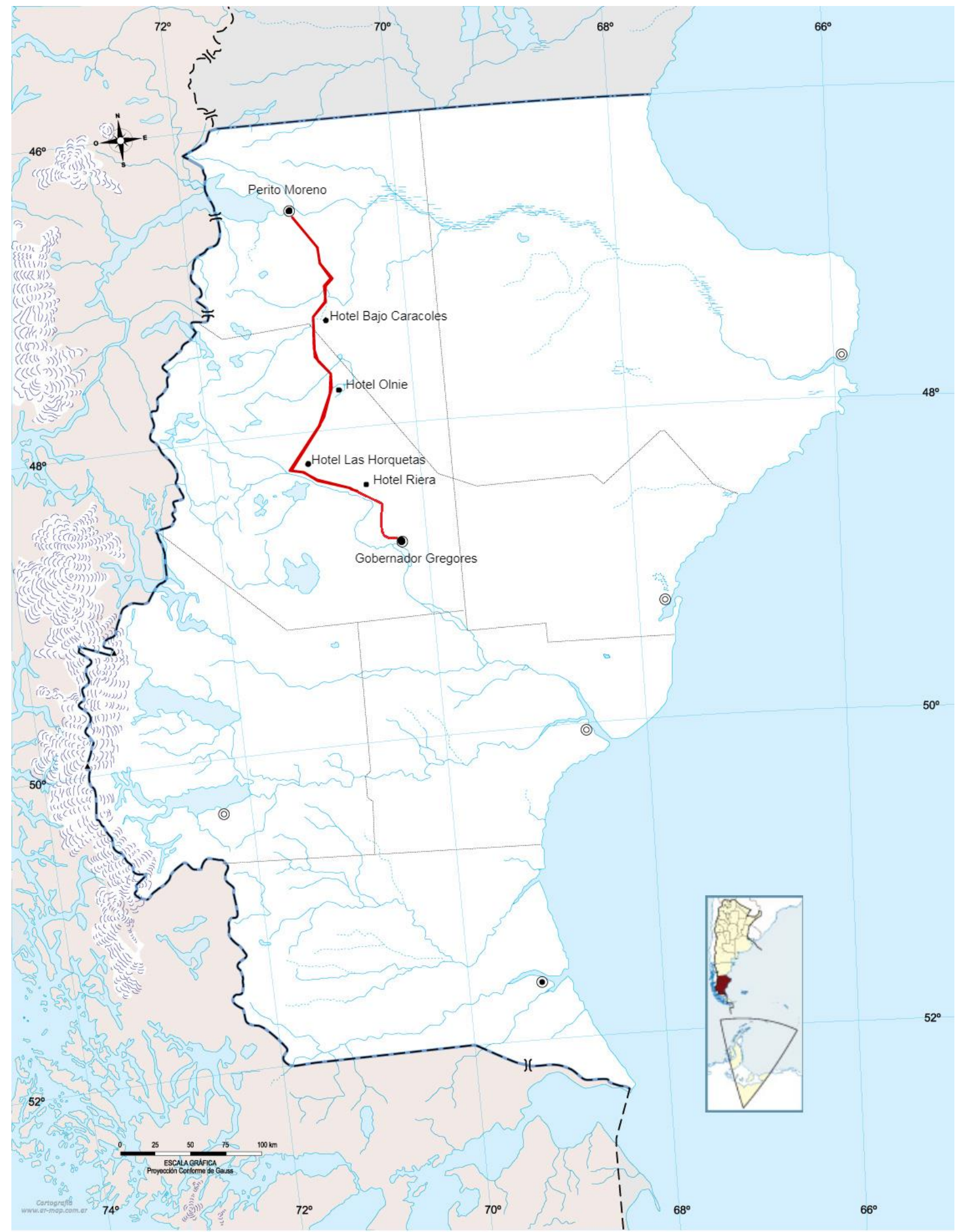

Ruta Nacional N ${ }^{\circ} 40$

(Figura 1) Área de estudio, correspondiente al NO de la actual Santa Cruz. Elaboración propia 


\section{Marco conceptual}

La realización de un diagnóstico actualizado y la puesta en valor de los recursos y actividades turísticas, existentes y potenciales, en la RN40, en su largo recorrido por la provincia de Santa Cruz, es la meta que se persigue para aportar al desarrollo de políticas y planes sectoriales sustentables. En la actualidad, el principal circuito de turismo organizado en Santa Cruz se apoya sobre los recursos naturales que ofrecen El Calafate y El Chaltén. No obstante, la provincia cuenta también con muchos otros destinos potenciales vinculados a la naturaleza o a su patrimonio cultural, que favorecerían el desarrollo de modalidades turísticas alternativas, tales como el turismo de intereses especiales, científico, cultural, observación de aves, rural, minero, entre otros (Schinelli y Vacca, 2007; Ferrari et al. 2009, 2013; Albrieu et al. 2010; 2012). Una importante cantidad de ellos aún no se ha puesto en valor; por el momento, constituyen recursos naturales/culturales más que atractivos turísticos.

En los últimos años, la demanda turística por sitios de patrimonio natural y cultural registra un crecimiento exponencial, tanto en el país como en el extranjero, y si bien la mayor parte de la actividad se desarrolla a través de lo que se conoce como turismo "masivo" o "convencional", existe un número cada vez mayor de turistas que busca contacto con la culturas autóctonas y con los espacios naturales. Estas nuevas formas de turismo que se están imponiendo rondan el $20 \%$ y ofrecen oportunidades casi exclusivas a Santa Cruz en virtud de la diversidad de recursos de los que dispone aún sin jerarquizar y que le confieren un abanico de productos capaz de atraer a mercados y segmentos ávidos en estas experiencias singulares (Secretaría de Ambiente y Desarrollo Sustentable de la Nación y PNUD, 2009).

Los hoteles de campo integran ese grupo de recursos culturales. Algunos de los que aquí se describirán ya son recursos turísticos mientras que de otros solo quedan ruinas. Sin embargo, ninguno ha sido abordado desde una investigación documental histórica. Los hoteles de campo de la RN40 presentan rasgos en común en cuanto a origen y función con aquellos que se han abordado en la región de Magallanes (Martinic, 2005) y el departamento de Güer Aike (Pierini y Beecher, 2014). La expansión de la actividad ganadera del siglo XIX y las dificultades del transporte y de las comunicaciones dieron lugar al surgimiento y desarrollo de estos paradores que fueron conectando toda la región:

"Los hoteles se fueron erigiendo siempre a la vera de las sendas o caminos más transitados o en las encrucijadas de los mismos (...) En los inicios de la vida del Territorio la ubicación se determinó de acuerdo con la distancia que los viajeros podían recorrer en una jornada por lo que estaban ubicados según las paradas de las chatas." (Pierini y Beecher, 2014: 8)

En muchos casos la administración de los hoteles corrió por cuenta de pequeños inversores que aprovecharon la oportunidad del desarrollo de la actividad comercial para invertir sus ahorros. Los hoteles se fueron construyendo no solo como apoyo logístico de la actividad ganadera, también fueron importantes centros para la socialización:

"El servicio que brindaban los hoteles de campo se fue ampliando con la provisión de comestibles en conserva, licores, bebidas, ropa, aperos, herramientas, armas y municiones. También comenzaron a recibir correspondencia actuando como estafeteros o correos. Los hoteles de campo cumplían un rol fundamental en el traslado de los habitantes de las zonas rurales y su importancia se acrecentaba en los instalados en lugares inhóspitos. Asimismo, y en el caso de sus propietarios, esta actividad les permitió acceder a información muy valiosa respecto a las condiciones de la tierra y la ganadería." (Pierini y Beecher, 2014:9). 


\section{Marco teórico}

La historia rural americana y argentina fue durante décadas sinónimo de la historia de la gran propiedad, con un análisis centrando en sus aspectos jurídicos, institucionales y legislativos (Fradkin, 1993). Desde este punto de partida es que la historiografía presenta, en general, el avance de la ganadería ovina desde una visión lineal, homogénea y simplificada. Se reduce a mostrar una economía y sociedad dominadas por la monoproducción ganadera y grandes terratenientes, sin lugar para el análisis de las dinámicas específicas de las regiones y de otros actores sociales (p.ej.: pequeños propietarios, peones, indígenas).

En Patagonia, un ejemplo de este tipo de abordaje se encuentra en la obra de Osvaldo Bayer (1986), quien denomina a la Patagonia Austral como el "far south", estableciendo una analogía con el sur esclavista estadounidense. En este sentido, en las páginas de "La Patagonia Rebelde" -obra emblemática para la historiografía de la región- se siguen los planteos habituales para abordar lo rural dentro de la comunidad historiográfica. Desde allí Bayer reflexiona:

“Qué era la patagonia en 1920? Podemos decir que era una tierra argentina trabajada por peones chilenos y explotada por un grupo de latifundistas y comerciantes. [Encontrábamos] Por un lado aquellos que han nacido para obedecer y, por el otro, los que se han hecho ricos porque son fuertes por naturaleza. Y allá, fuerte quiere decir casi siempre inescrupuloso" (Bayer, 1986).

El enfoque que aquí se propone, al incorporar nuevas preguntas sobre la conformación del espacio rural -tomando los hoteles de campo y el transporte de la lana como unidades de análisis- busca complejizar la visión económica, demográfica y social sobre un periodo con una importancia trascendental para la conformación del TNSC. Estas nuevas formas de estudiar lo rural, son una herencia de un cambio de paradigma en la historiografía, dado por el pasaje desde una visión estructural de la historia a otra que comenzó a poner de relieve una cierta libertad de acción de los actores colectivos e individuales que podían incidir, a veces de manera decisiva, en la conformación general de la sociedad (Gelman, 2007).

\section{RESULTADOS ANÁLISIS Y DISCUSIÓN}

\section{Materiales y métodos}

Se llevó adelante el análisis de los hoteles de campo siguiendo la metodología de registro e inventario de los recursos naturales y culturales con potencial atractivo turístico (Ferrari et al 2013 y Navarro et al 2013), sobre la base de otras metodologías (OEA-Cicatur 1978, Ceballos Lascuraín 1998 y MINCETUR 2006). Esta incluye cuatro grupos de atractivos: a) recursos naturales; b) recursos culturales; c) recursos técnicos-científicos; d) reuniones y acontecimientos programados. Luego se establece una valoración de cada recurso a través de diez criterios a los que se les asignó una categoría (muy bueno, bueno, regular y malo) y un valor a cada uno (de 6 a 1). Los criterios contemplan los datos sobre asignación del grupo, tipo del recurso, localización espacial, distancia del centro turístico más cercano, propiedad, aspectos referidos a la conservación del recurso y su entorno, accesibilidad, particularidad del recurso, vulnerabilidad, servicios e instalaciones. La evaluación asigna un factor de ponderación a aquellos criterios que se consideran más sobresalientes y que son decisivos a la hora de definir un recurso con valor turístico (por ejemplo, la Particularidad). De esa ponderación se obtiene el valor final por cada recurso inventariado y se procede a su jerarquización. 
Se realizó una búsqueda bibliográfica referida a los hoteles de campo y la actividad ovina en la región. En esta búsqueda es que, desde la perspectiva de la historiografía, se profundizó en lo referido a la caracterización de las funciones pasadas de los hoteles y la conformación del espacio rural del NO de Santa Cruz, tomando las siguientes variables de análisis: el periodo de asentamiento de los hoteles, los perfiles de los propietarios de los establecimientos, las actividades económicas asociadas al tipo de ocupación, la estructura edilicia y la forma de tenencia o propiedad de la tierra. Asimismo, se confeccionaron y realizaron entrevistas a modo de consulta con investigadores en la temática.

La labor desarrollada se inició con el reconocimiento, identificación y localización de los hoteles de campo en el área de estudio (NO de Santa Cruz, tramo Gobernador Gregores Perito Moreno de la Ruta $\mathrm{N}^{\circ} 40$ ). Al respecto se ha logrado identificar la existencia de cuatro hoteles de campo: "Riera", "Horquetas", "Olnie" y "Bajo Caracoles". Los cuatro sitios fueron localizados en una cartografía elaborada ad-hoc (Figura 1).

Desde estas bases se procedió a la etapa de investigación documental, indagando fuentes inéditas y directas - tales como los registros comerciales de los correspondientes locales y sus dueños- y fuentes secundarias y éditas -tales como algunos testimonios realizados por contemporáneos dedicados al seguimiento de la actividad económica del TNSC, fuentes periodísticas y obras de la historiografía regional.

El Archivo Histórico Provincial de Santa Cruz brindó la información más relevante en cuanto a fuentes directas, particularmente en su sección "Fondo de Gobernación de Santa Cruz (1884-1955)", cuyos expedientes se encuentran inventariados y los resúmenes de sus extractos disponibles para consulta, lo cual permitió dar con la búsqueda de información sobre los hoteles de campo de interés a la investigación. Al respecto, esta investigación tuvo como base el relevamiento de más de quinientos expedientes del citado fondo (Tabla 1).

\begin{tabular}{|l|l|}
\hline Sitio de interes & $\begin{array}{l}\text { Expedientes } \\
\text { relevados }\end{array}$ \\
\hline Rio Olnie & 4 Expedientes \\
\hline Bajo Caracoles & 46 Expedientes \\
\hline Las Horquetas & 11 Expedientes \\
\hline Cañadón León & 412 Expedientes \\
\hline Tamel Aike & 146 Expedientes \\
\hline Nacimiento & 153 Expedientes \\
\hline Lago Buenos Aires & 54 Expedientes \\
\hline Colonia Sáenz Peña & 42 Expedientes \\
\hline Colonia Leandro Alem & 8 Expedientes \\
\hline
\end{tabular}

Tabla 1. Cantidad de expedientes relevados según sector.

Junto a los expedientes, se relevaron fuentes periodísticas, en particular números pertenecientes al semanario "El Sonido" de Puerto San Julián entre los años 1950-1957 y documentación oficial del periodo: Libros copiadores del gobierno de Juan Manuel Gregores, Informes de inspección de tierras, el registro de marcas de ganado mayor y estadísticas referidas a los propietarios ganaderos y formas de tenencia de la tierra.

El relevamiento de los expedientes seleccionados se realizó de forma individualizada a cada hotel. Considerando de interés aquellos expedientes citados en este trabajo. 
El problema de los transportes y las actividades comerciales se realizó tomando una escala regional, sumando a las localidades de Nacimiento (actual Perito Moreno) y Cañadón León (actual Gobernador Gregores) abarcando un área de $246 \mathrm{~km}$. La información obtenida de los expedientes acerca de las actividades y administradores de los hoteles de campo fue contrastada con datos brindados por otras fuentes, especialmente aquellos estudios realizados por contemporáneos como Edelmiro Correa Falcón (1924), Saúl Cuasmicú (1935), relevamientos oficiales (registros de boletos de marca, listado de propietarios elaborados por la gobernación), relevamientos realizados dentro del campo de la historiografía regional y las fuentes periodísticas consultadas.

Junto al relevamiento historiográfico y con fines de contribuir al desarrollo de un inventario sistematizado y actualizado de los recursos y actividades culturales, tarea de importancia para el estudio y evaluación de posibles productos y circuitos turísticos (Almendras, Ferrari y Diez 2016), se procedió a la caracterización y jerarquización de los recursos culturales identificados como hoteles de campo en el corredor de la Ruta Nacional No40 (Tramo Gobernador Gregores - Perito Moreno) empleando las metodologías mencionadas supra.

\section{Resultados}

\section{Asentamientos en el NO de Santa Cruz}

Un primer panorama sobre la región del NO de Santa Cruz fue trazado por los distintos relatos y observaciones de viajeros que se acercaron hasta el área de estudio navegando sus grandes lagos y recorriendo su paisaje cordillerano en busca de lugares óptimos para una posible explotación económica. Según Halvorsen (2009), Viedma (1782), Perito Moreno (1877), Hesketh Prichard (1901) y la Expedición Magallánica Sueca (1907) coinciden en mostrar un cuadro de zona despoblada. Este panorama desolador perdurará hasta la segunda década del siglo XX, donde la consolidación de establecimientos ganaderos comenzará a retocar la fisonomía de la región ${ }^{4}$.

\footnotetext{
3 Durante la etapa de predominio de la ganadería ovina, el poblamiento urbano de la cordillera será escaso y la distribución de la población mantuvo un alto porcentaje de ruralidad. Un informe de septiembre de 1939, elaborado por la Gobernación del Territorio Nacional de Santa Cruz, estima que la población del Departamento de Lago Buenos Aires ascendía a los 1.769 habitantes, de los cuales sólo 568 pertenecían a la localidad de Lago Buenos Aires (actual Perito Moreno) y 165 a Los Antiguos.

$4 \quad$ Lejos de ser un "desierto", el territorio del NO de Santa Cruz se destaca por una marcada presencia indígena, evidenciada por el registro histórico y arqueológico. Por caso, vale mencionar el peso que jugaron las comunidades indígenas en los relatos de los primeros colonizadores de la actual localidad de Perito Moreno, quienes han transmitido su toponimia original "Pari Aike" en los principales relatos y crónicas fundacionales locales. Más información en: (2006) Revista de Interinformación Zonal. Año I, №2.
} 


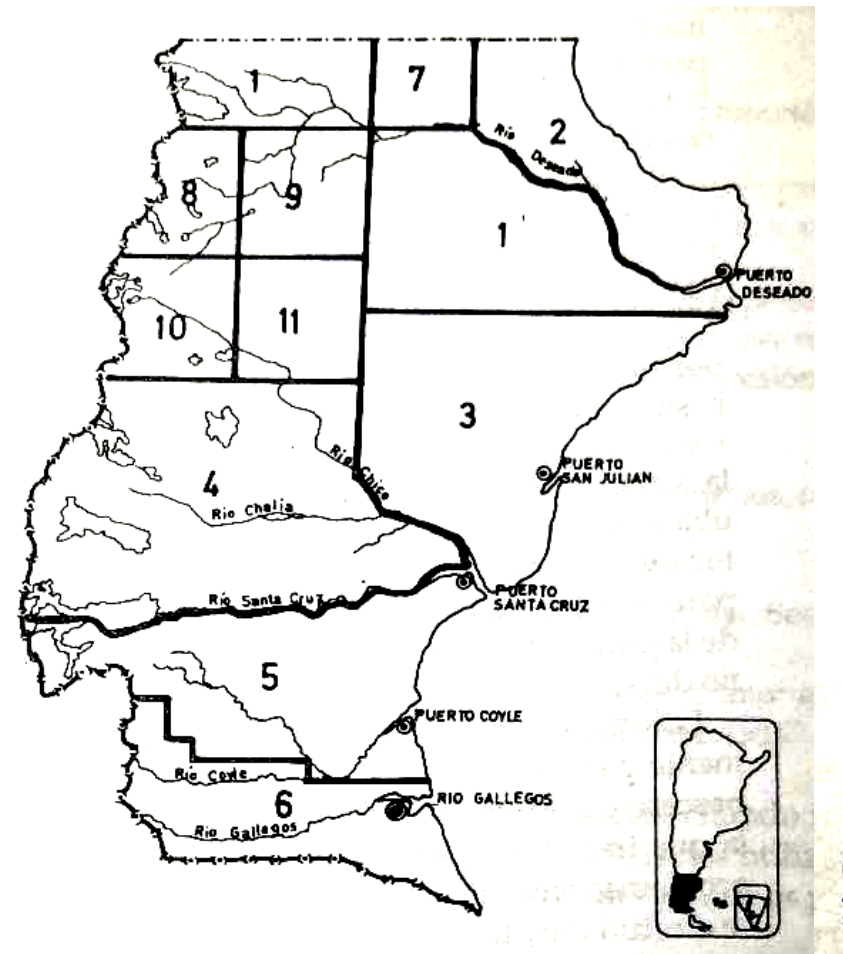

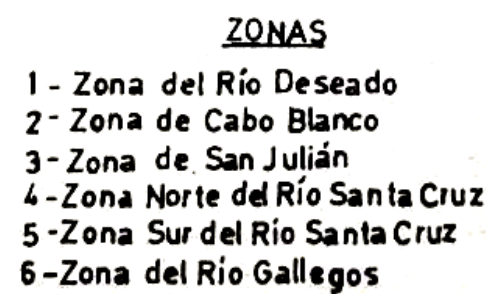

COLONLS

7-Colonia Las Heras

8. Colonia Pie. Manuel Quin tana

9-Colonia Pte Car los Pellegrini

10-Colonia General Paz

II-Colonia Ple. Luis Saénz Peria

(Figura 2) Subdivisión territorial del TNSC (Barbería 1995)

Después de algunos viajes exploratorios por la región, en 1908 la Gobernación del Territorio Nacional creará cinco colonias destinadas a la ocupación del área cordillerana: Colonia Las Heras, Colonia Manuel Quintana, Colonia Carlos Pellegrini, Colonia General Paz y Colonia Sáenz Peña. A las cinco colonias ya establecidas, en 1921 se sumará la Colonia Leandro Alem en el área de Zona del "Río Deseado" (Figura 2).

Según Barbería (1995) las primeras colonias en recibir pobladores serán la Colonia Manuel Quintana y la Colonia Sáenz Peña. Figuran como colonizadores de este espacio, previo al año 1914, Federico y Carlos Kogler, Guillermo Dreizler, Felipe Kaiser y Carlos Schloz. Estos establecimientos serán producto de un contrato firmado con la Sociedad Germano-Argentina de Colonización, institución que facilitaría la instalación de colonos en el territorio ${ }^{5}$. La entrega de tierra por medio de la figura legal de colonización se encontraba contemplada en la Ley General de Tierra Nª167, sancionada en 1903. Los inmigrantes europeos interesados en establecerse en estos espacios debían tener menos de cincuenta años, instalarse con su familia y contar con un certificado de buena conducta y salud. Este contrato rubricado en 1910 será rescindido por el incumplimiento de la mencionada sociedad. En virtud de las inversiones que realizaron en la Colonia Sáenz Peña, se les adjudicó un lote a los inmigrantes europeos que arribaron por su intermedio, a razón de \$1,50 moneda nacional la hectárea (Barbería, 1995).

Esta misma autora contabiliza la presencia de sólo 51 productores hacia la década de 1920 en toda la zona de la Colonia Manuel Quintana, de los cuales sólo 5 son propietarios, ocupando

\footnotetext{
5 Durante fines del siglo XIX e inicios del siglo XX las empresas colonizadoras fueron organizadas con los fines de atraer inmigrantes de origen europeo para la colonización del territorio. Algunos ejemplos serán las colonias "Friedland" en Río Pico y la Compañía Germano Argentina en Santa Cruz. Según Ernesto Maggiori (2009) Las empresas de colonización alemana en la Patagonia si bien lograron radicar familias en forma individual y particular, no resultaron prósperas en tanto empresa organizada y colectiva. Ver más información en Ernesto Maggiori (2009) Colonias Alemanas en la Patagonia. Vela al viento. Ediciones Patagónicas.
} 
un total de 127.350ha. En la Colonia Sáenz Peña registra, asimismo, nueve concesiones en calidad de colonos, con ocupaciones que abarcaban una superficie de 2.500ha cada una. Según Barbería (1995), la Colonia Manuel Quintana y la Colonia Sáenz Peña presentan comparativamente con la región al sur del río Santa Cruz- adjudicaciones escasas y marginales; de allí que la autora no haya profundizado en el estudio de la forma de distribución de la tierra en esa región. La Colonia General Paz y la Colonia Carlos Pellegrini tampoco son abordadas ya que -según precisa la historiadora- "no presentan ocupaciones" (Barbería, 1995: 314). No obstante estas afirmaciones, en el transcurso de la década de 1920, los libros de Inspecciones de Tierra que hemos relevado arrojan testimonios acerca de la ocupación incipiente de lotes, tanto en la Colonia General Paz como en la Colonia Carlos Pellegrini, escenarios donde luego -hacia la década de 1930- se asentaran algunos hoteles de campo aquí estudiados. Este hecho particular nos muestra que los estudios acerca de la distribución de la tierra, en la vasta extensión del TNSC, aún presentan márgenes inconclusos dentro de la historiografía regional.

\section{Hoteles de campo}

Los hoteles de campo del NO del TNSC forman parte del fenómeno de expansión de la actividad ovina en toda la región. Como ya se ha dicho, el origen de estos hoteles de campo bien puede emparentarse con los ubicados al sur del río Santa Cruz. No obstante ello, tres serán los rasgos que se juzgan representativos de las diferentes trayectorias entre los establecimientos del Sur y los establecimientos que aquí describiremos. En primer lugar, en el Sur existirá un temprano establecimiento de casas de comercio en la zona, con permisos documentados en años previos al $1900^{6}$. En segundo lugar, la actuación de sociedades ganaderas será otro rasgo que diferenciará los establecimientos del Sur, donde prevalecen las instalaciones de las principales sociedades anónimas del territorio por encima de los simples ocupantes, arrendatarios o colonos que serán los protagonistas en el $\mathrm{NO}^{7}$. En tercer lugar, y vinculado a la presencia de otro volumen de capitales, los establecimientos del Sur presentarán una actividad comercial más intensa en comparación con la zona del NO, que incluirá una intensa actividad de exportación y de importación ${ }^{8}$.

Los hoteles de campo, en tanto espacios de socialización, intercambio comercial y estadía, se encuentran ligados al poblamiento rural y al particular desarrollo de los transportes de lana de tracción a sangre que aquí describiremos. Es así que las prolongadas distancias entre los puertos y los establecimientos productivos se vieron pobladas por hoteles, que se constituyen en un producto típico de este tipo de ocupación del espacio rural orientada a la exportación.

A la luz de este proceso general es que situamos el surgimiento de los hoteles "Riera", "Las Horquetas", "Olnie" y "Bajo Caracoles" (Figura 1). Si bien estos hoteles comparten un origen común, su trayectoria será divergente. Mientras que en los actuales emplazamientos de "Riera" y "Olnie" encontramos solo ruinas, "Las Horquetas" y "Bajo Caracoles" continúan siendo dos paradores de importancia estratégica para los viajeros que tanto abundan en la Ruta Nacional No40 (Figura 3).

\footnotetext{
$6 \quad$ Entre los años 1897 y 1900 los particulares Riquez y Rodríguez, Francisco Cid y Rich y Rodríguez (entre otros) solicitaran permisos para establecer negocios en el actual departamento de Guer Aike.

$7 \quad$ Fondo de Gobernación (1884-1955). Archivo Histórico Provincial. Expediente 2950/1917.

8 Las fronteras no impedían los negocios. Por ejemplo, la "Sociedad Anónima Ganadera Suarez Laudoch" en concepto derecho a la exportación hacia Chile -solamente para el año 1922- abonará \$172,59 pesos argentinos. Fondo de Gobernación. Op. cit. Expedientes: 018/1922, 530/1922, 531/1922, 632/1922.
} 


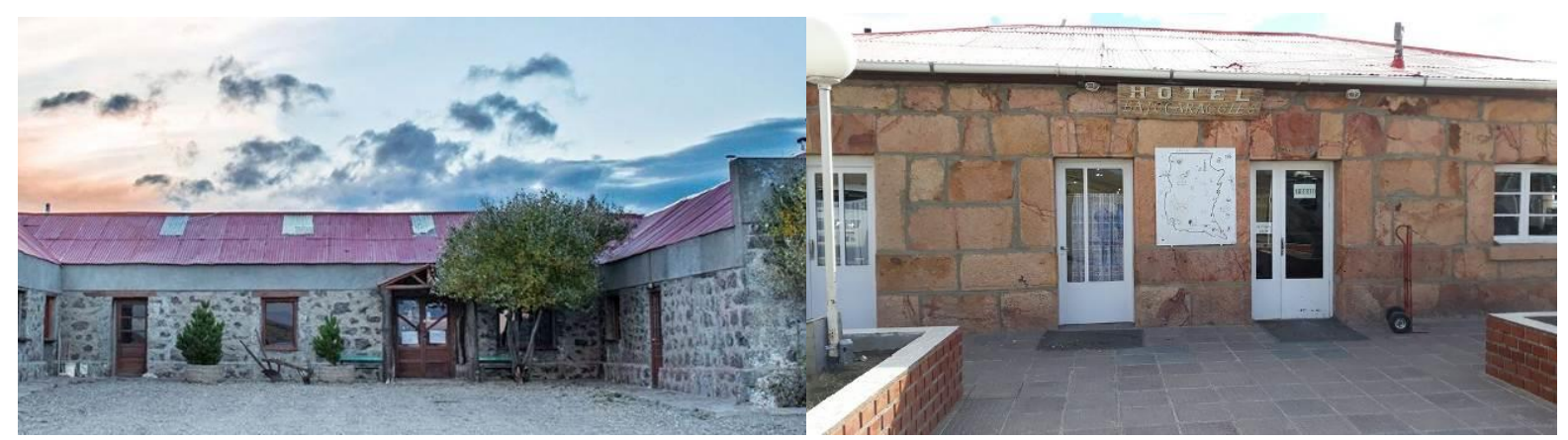

(Figura 3) Los Hoteles “Las Horquetas" (Izquierda) y “Bajo Caracoles” (Derecha) en la actualidad.

Fotos correspondientes a la información turística brindada por los propios hoteles.

Para la descripción de los hoteles de campo tendremos en cuenta el orden de paradas señaladas por un viajero (El Sonido, 1953) que se dirige desde la localidad de Cañadón León hacia la Cordillera. El trayecto -tomando en cuenta solamente a los hoteles aquí estudiadosrespondía al siguiente orden: "Casa Riera", "Las Horquetas", "El Olnie" y "Casa Folch" (Bajo Caracoles) (Figura 4).

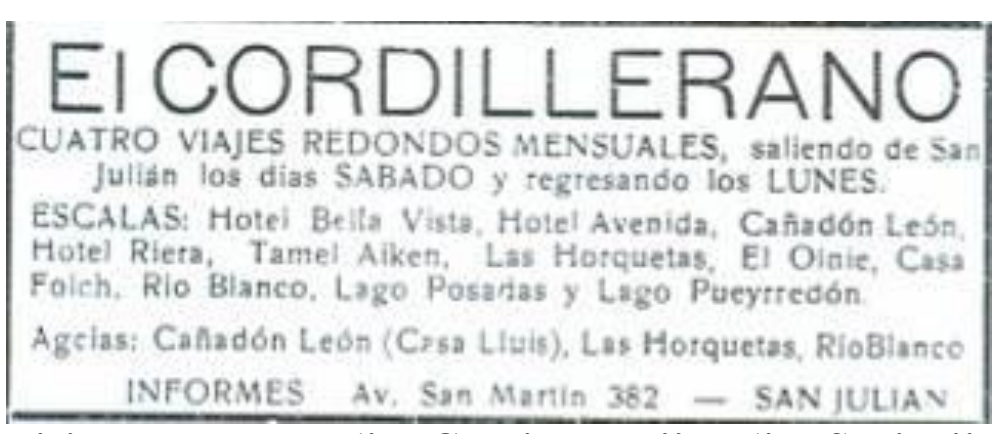

(Figura 4) Publicidad transporte 'El Cordillerano" en 'El Sonido' de Puerto San Julián (1955)

Los registros del viajero -cuyo nombre desconocemos- se realizaron a bordo del transporte "El Cordillerano" que conectará la región en tiempos recientes. Sus impresiones nos dan una idea de la actividad de los hoteles Riera, Horquetas, Olnie y Bajo Caracoles, los cuales se encontraban en funcionamiento en su totalidad hacia la década de 1950, formando parte de una misma ruta de tránsito de personas, bienes, correspondencia y encomiendas.

La importancia de cada uno de estos paradores revelados por el viajero nos muestra una primera conversión de estos hoteles. Los mismos -construidos durante las décadas de 1920 y 1930 con fines de abastecimiento al transporte de fardos de lana desarrollado mediante caravanas de chatas, carros y carretas- continuaron brindando servicios de apoyo a los viajeros ahora movilizados sobre el trazo de la Ruta Nacional №40 (que durante mediados de la década de 1950 era de ripio) en transportes de tracción mecánica.

Esto revela que la modificación de tecnologías de transporte y la constitución de la red caminera en la provincia no resultaron un factor definitivo en la desaparición de los hoteles de campo tal como señalan Cerrato (2000) y Halvorsen (2009). Como se verá, al menos en los hoteles de campo aquí relevados, pesaron en su cierre modificaciones en cuanto a la venta y administración de los mismos, sucesiones familiares o modificaciones en inversiones. 


\section{Hotel "Riera"}

El hotel Riera data del año 1927. Será en ese año cuando Antonio Riera, español, vecino de la localidad de Puerto San Julián, solicita la instalación de un negocio de ramos generales (tienda y almacén). El hotel se encontrará dentro de la Colonia Sáenz Peña, bajo jurisdicción de la Comisaría de Tamel Aike. Para el establecimiento del comercio, Riera deberá solicitar permiso a Eusebio Jara, quien arrendaba por entonces aquellos lotes ${ }^{9}$.

A diferencia de los otros hoteles, "Riera" muestra la presencia de un inversor foráneo al área de estudio. Este hecho marca la variedad que existía entre los perfiles de los propios administradores de los hoteles de campo y las posibilidades de una inversión rentable que significaba la instalación de un hotel en un espacio ampliamente transitado por chatas, carros y carretas (Figura 9).

Hotel Riera se destaca por ser un espacio construido para brindar confort al viajero, siendo muy bien referenciado por la iniciativa de su dueño, que contaba con posibilidades de inversión que facilitaron la instalación de un campo de aterrizaje en el área:

"Existe alli un campo de aterrizaje en buenas condiciones y debidamente demarcado, que se debe a la iniciativa del dueño del hotel, Sr. Antonio Riera, y a la colaboración de pobladores vecinos. Este campo está llamado a cumplir alta finalidad por cuanto en la época invernal, ya sea por la nieve o el barro, es muy difícil sino imposible salir de allí. Se recurre entonces a la aviación, especialmente en casos urgentes de enfermedad u otras situaciones de apremio (...) Luego de un buen almuerzo -tan bueno como el que podría obtenerse en cualquier hotel de San Julián- seguimos en viaje en dirección a Tamel Aiken, distante unas siete leguas de alli’.' (El Sonido, 27 de marzo de 1953: 3)

La cita del viajero marca las dificultades de los caminos de la época, que por ser de ripio estaban muy expuestos a la acción de la lluvia, la nieve o el invierno, dificultad que intentaba ser saldada mediante los servicios aéreos impulsados durante la gobernación de Juan Manuel Gregores que fueron conectando el vasto TNSC durante la década de 1930.

El hotel presentará una larga trayectoria en la región, principalmente por su ubicación estratégica (situado casi a la vera del Rio Chico) y por ser lugar de paso desde Cañadón León hacia la cordillera, siendo la primera escala para los viajeros que parten desde esta localidad. Fue lindante a la comisaría de Tamel Aike, cabecera del departamento de Río Chico y sede del Juzgado de Paz de la jurisdicción. Este espacio contará, al igual que la región de Bajo Caracoles, una gran cantidad de establecimientos ganaderos a sus alrededores, tal como evidencian los boletos de marca registrados en la zona de Tamel Aike hacia 1930.

Según consta en un aviso comercial realizado por el mismo Antonio Riera (Figura 5), las instalaciones del hotel fueron transferidas a los compradores Antonio Martínez y Mauro Martínez, quienes serían beneficiados en 1957 con lotes en la misma colonia (El Sonido, 1957). Desconocemos las razones de la venta, aunque sin lugar a dudas tuvo como principal consecuencia para Antonio Riera el fin de más de un negocio que llevó de forma ininterrumpida durante más de 30 años.

$9 \quad$ Fondo de Gobernación (1884-1955). Archivo Histórico Provincial. Expediente: 1444/1927. 


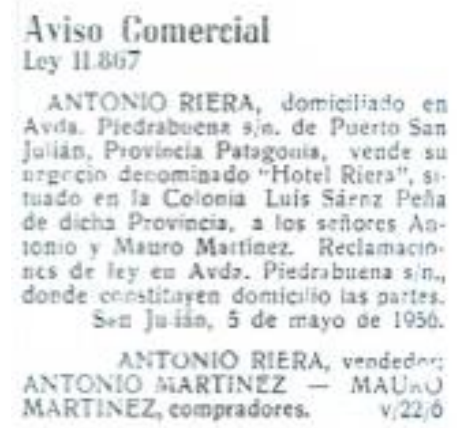

(Figura 5) Aviso comercial realizado por Antonio Riera (El Sonido, 1956)

\section{Hotel "Las Horquetas"}

Se tiene registro del funcionamiento del paraje Las Horquetas desde fines de la década de 1920. En el año 1932 se establece Amador Álvarez, quien organizará un negocio en los ramos de tienda, fonda, tabacos, bebidas alcohólicas por copas y acopio de frutos locales. El Hotel se encontraba ubicado en el lote 5 de la Colonia General Paz y estaba bajo jurisdicción de la comisaría de Tamel Aike ${ }^{10}$.

Las "Horquetas" que se abren sucesivamente a medida que se avanza por el camino han dado nombre al lugar y hotel. Como destaca la imagen de su fachada actual (Figura 3) el hotel y la mayoría de las construcciones de la zona son de "rústica piedra" (El Sonido, 1953).

Siguiendo una trayectoria con rumbo hacia el oeste, el hotel Las Horquetas dista a 15 kilómetros de la comisaría de Tamel Aike, sitio que conecta este hotel con Riera. No obstante la proximidad de Las Horquetas y Tamel Aike, el constraste entre ambos poblados es muy marcado. De la comisaría de Tamel Aike nuestro viajero dirá "El lugar me parece bastante triste y pienso que no deja de ser un sacrificio el que realiza el personal policial destacado alli" (El Sonido, 1953). La opinión sobre Las Horquetas será completamente opuesta, donde nos muestra la vitalidad que presentaron estos lugares como espacios de socialización:

"Punto de reunión de pobladores y trabajadores rurales los domingos y días feriados; a pesar de mediar la considerable distancia de 350 kilómetros entre él y San Julián, tuve la impresión de que no se experimenta alli la sensación del aislamiento, y siempre se encuentran personas conocidas que se interesan por las novedades del "poblao", del cual debido a ese mismo interés muchas veces están más al corriente que nosotros los puebleros". (El Sonido, 27 de marzo de 1953: 3)

El 22 de febrero de 1935 los edificios que componen el hotel fueron adquiridos por la Sociedad "Iriarte y Fernández". El traspaso de los bienes tuvo como trasfondo una decisión del Juzgado Letrado del Territorio, que dispuso el desalojo de Amador Álvarez, quien poseía los terrenos en calidad de arrendatario. Este último, luego, solicitará instalarse en Pico Truncado $^{11}$.

El desalojo marcará dos aspectos claves con respecto al poblamiento del NO de Santa Cruz: el predominio de los arrendatarios por sobre los propietarios efectivos y la permanente

10 Fondo de Gobernación (1884-1955). Archivo Histórico Provincial. Expediente: 031/1935. Adjunto al expediente, un informe del cuerpo policial señala que el administrador no registra antecedentes judiciales ni policiales, hecho que marca que la buena "conducta" era un factor a considerar en la habilitación de un comercio en la época.

11 Fondo de Gobernación (1884-1955). Archivo Histórico Provincial. Expediente: 1945/1939. 
inestabilidad a la cual eran sujetos estos arrendatarios, muchos de los cuales fueron ocupantes que establecieron actividades en la zona, y que luego serían desalojados en beneficio de aquellos que contaban con capital, pese a ser en gran parte propietarios absentistas. Las consecuencias de este proceso las describió Barbería (1995) como una política de administración de la tierra llevada adelante por las sucesivas gobernaciones del Territorio Nacional de Santa Cruz que privilegiaron el capital sobre el trabajo y que conllevó la concentración de tierras y el despoblamiento del espacio rural.

En el año 1937, será por orden del Juez de Paz de Cañadón León (Oficio 2365) que se pondrán los inmuebles en posesión de Eladio Fernández, en tanto sucesor de la disuelta sociedad "Iriarte y Fernández". Será Eladio Fernández quien en 1938 solicitará ante el Gobernador del Territorio la transferencia del permiso de la bebida al detalle. La misma será otorgada por la Gobernación del Territorio el 6 de octubre de $1938^{12}$.

\section{Hotel "Río Olnie"}

Siguiendo una trayectoria con rumbo norte, el hotel "Olnie" se encontraba a la considerable distancia de 70 kilómetros desde "Las Horquetas". El trayecto del camino, antes del trazo de la Ruta Nacional $\mathrm{N}^{\circ} 40$, se encontraba marcado por huellas en distintas direcciones, en general orientadas hacia los establecimientos del área de la cordillera y el Lago Pueyrredón (Figura 9). En el camino que separa "El Olnie" de "Las Horquetas" estaban los buzones de las estancias "La Cantera" de Esteban Zart, "El Valle" de Bockelmann y "La Fe" de Rodríguez, entre otras (El Sonido, 1953).

Se registran datos históricos acerca del funcionamiento de "Hotel Río Olnie" a partir de la década de 1930. Se encontraba ubicado en el Lote 22, Fracción C, de la Colonia Carlos Pellegrini ${ }^{13}$. El hotel estaba bajo jurisdicción del destacamento de policía de Tamel Aike y estuvo bajo administración de Esteban Karmelic y Nicolás Cvjetanovic ${ }^{14}$. Debe su nombre al rio homónimo a la vera del cual estaba emplazado.

El parador funcionó como tienda comercial, fonda con bebidas alcohólicas y como sitio de acopio de frutos del país. Cuasmicu (1935) menciona al señor "Centanovic, Nicolás" de "El Olnie" en su registro de ganaderos del Territorio. Este dato nos permite evaluar que la ganadería no era una actividad ajena al propio hotel. Por el contrario, las fuentes indican que fueron los mismos ganaderos ya establecidos quienes constituyeron los primeros hoteles y paradores de campo en sus estancias particulares. Será el mismo protagonista, Nicolás Cvjetanovic, quien en 1938 solicitará permiso de vendedor ambulante en el Territorio ${ }^{15}$. El perfil multifacético del administrador del hotel antes citado- en su carácter de comerciante, acopiador de frutos, ganadero y mercachifle- nos muestra el volumen de las actividades económicas existentes en la región.

El funcionamiento del parador como sitio de acopio de frutos del país se relaciona estrechamente con la actividad lanera. El acopio de frutos era la expresión de época utilizada entre los registros oficiales para designar aquellos espacios destinados al almacenamiento de los fardos de lanas de producción local destinados a la exportación. Este permiso en particular 
iguala los hoteles "Las Horquetas" y "El Olnie" con un perfil ganadero más marcado en comparación con "Riera", más ligado a la atención de viajeros.

El hotel también dejó registros de una historia marcada por la violencia. En 1936, se instruye sumario administrativo sobre el sitio en la Subcomisaría de Tamel Aike por un hecho de sangre ocurrido en el Hotel, donde Carlos Ríos hiere a Ramón Rodríguez ${ }^{16}$. En 1937, será la Subcomisaría de Lago Posadas la que eleve las actuaciones de un nuevo hecho de sangre en "Río Olnie", en el cual fallece Gabriel Pinto, trabajador de la Ea. "La Esther"17.

Nicolás Cvjetanovic tendrá una larga trayectoria como ganadero. Será designado delegado especial de la zona Roballos por la Sociedad Rural de Puerto San Julián en el año 1954. Al igual que muchos ocupantes de tierras, en el año 1957 resultará beneficiado con la adjudicación en venta de 15.000ha ubicadas en el Colonia Manuel Quintana (Lote 16 y parte del lote 21, fracción B) (El Sonido, 1957). Su especialización dentro de este rubro determinará su desentendimiento del hotel, que luego sería administrado por Eliseo López.

\section{Hotel "Bajo Caracoles"}

Rumbo hacia el norte, 30 kilómetros distan entre "El Olnie" y el Hotel "Casa Folch" situado en el parador "Bajo Caracoles". El difícil trazo del camino representaba adversidades a los viajeros de la región:

"Ciertas partes de la ruta, bastante dificiles, exigen la máxima prudencia del conductor que, consciente de ello y de su responsabilidad, sabe hacerse cargo de la situación con la mayor eficiencia: en este aspecto, hay que señalar en forma especial la bajada de Caracoles, que de allí tiene su nombre por los múltiples recovecos que describe, donde cualquier vehículo "largado" en directa iría irremisiblemente al desastre porque no habría freno capaz de detenerlo" (El Sonido, 27 de marzo de 1953: 3)

"Casa Folch" será el hotel característico de la localidad Bajo Caracoles, (actualmente lleva el mismo nombre que el parador que le dio origen). En el periodo estudiado, el hotel se destacaba por brindar servicio de hospedaje y su excelente servicio de cocina (El Sonido, 1953). El Hotel "Bajo Caracoles" presenta registros de actividades desde la década de 1930, el mismo será propiedad de José Folch ${ }^{18}$, quien en 1937 solicitará permiso para el expendio de bebidas al detalle en su casa de comercio ${ }^{19}$. Folch será un reconocido empresario de la zona, especializado también en la prestación de servicios de correo. Hacia mediados de 1953 el hotel sería administrado por Oscar Izaguirre.

"Bajo Caracoles" será un sitio de referencia por su ubicación estratégica, en la encrucijada de caminos que conducen hacia Nacimiento, Paso Ceballos y los Lagos Posadas y Pueyrredón. Se ubica, asimismo, en una región poblada de estancias y ganado ${ }^{20}$ (Figura 6).

\footnotetext{
16 Fondo de Gobernación (1884-1955). Archivo Histórico Provincial. Expediente: 5522/1936.

17 Fondo de Gobernación (1884-1955). Archivo Histórico Provincial. Expediente: 1677/1937.
}

18 En el año 1936 la Subcomisaría de Lago Posadas establecerá una denuncia contra José Folch por festejos en el Hotel. La razón de la denuncia responde a los dictados de la ley 4097/1902 que prohibía los juegos de azar, entre ellos las tradicionales carreras de pollas y sortijas que solían celebrarse con motivo de las festividades. Fondo de Gobernación (1884-1955). Archivo Histórico Provincial. Expediente 4233/1936.

19 Fondo de Gobernación (1884-1955). Archivo Histórico Provincial. Expediente 0293/1937.

20 En 1953 se establecerá la clausura del establecimiento "Bajo Caracoles" de Jose Folch con motivo de la existencia de sarna en el Departamento de Río Chico 19. La clausura se levantará ese mismo año. Fondo de Gobernación (1884-1955). Archivo Histórico Provincial. Expediente 4271/1953. 


\begin{tabular}{|l|l|l|}
\hline \multicolumn{1}{|c|}{ Estancia } & \multicolumn{1}{c|}{ Particular } & \multicolumn{1}{c|}{ Boleto de marca } \\
\hline "El porvenir" & Luis Llape & $\mathrm{N}^{\circ} 2785$ \\
\hline "Los Manantiales" & Filiberto Mansilla & $\mathrm{N}^{\circ} 2822$ \\
\hline "Casa Blanca" & Luis Muñoz & $\mathrm{N}^{\circ} 2308$ \\
\hline "El Pedregal" & Miguel José Maieres & $\mathrm{N}^{\circ} 1738$ \\
\hline "Cerro Chato" & Joaquín Mujica & $\mathrm{N}^{\circ} 2268$ \\
\hline "Cerro Poivre" & José Camilio Pardo & $\mathrm{N}^{\circ} 2806$ \\
\hline "La Criolla" & José Eleazar Aguilar & $\mathrm{N}^{\circ} 2769$ \\
\hline "El Trébol" & José Elarriaga & $\mathrm{N}^{\circ} 2817$ \\
\hline "El Ghio" & Nicolás Fernández & $\mathrm{N}^{\circ} 2611$ \\
\hline "La Victoria" & Oreste Graglia & $\mathrm{N}^{\circ} 2448$ \\
\hline Lote 8. Fracción D & Clemente Álvarez & $\mathrm{N}^{\circ} 2814$ \\
\hline "Cañadón Las Vacas" & José Espina Álvarez & $\mathrm{N}^{\circ} 1737$ \\
\hline "La Irenita" & Antonio Bulat & $\mathrm{N}^{\circ} 2653$ \\
\hline "Rio Blanco" & Enrique Grant & $\mathrm{N}^{\circ} 1311$ \\
\hline "El Olvidado" & Roberto Aguilino Garriz & $\mathrm{N}^{\circ} 1740$ \\
\hline "Cerro Negro" & Nicasio Castañón & En trámite \\
\hline "La Península" & Emma Miglio & $\mathrm{N}^{\circ} 1444$ \\
\hline "La Lucha" & Rafael Navarta Segovia & $\mathrm{N}^{\circ} 2190$ \\
\hline "San Francisco" & Martín Garriz & $\mathrm{N}^{\circ} 1856$ \\
\hline "Santa Rita" & Juan Rogelio Vera & En trámite \\
\hline "La Paloma" & Pedro Kovasic & $\mathrm{N}^{\circ} 2815$ \\
\hline "Zorro Bayo" & Miguel Arruti & $\mathrm{N}^{\circ} 2347$ \\
\hline "El Mirasol" & Francisco Garibay & En trámite \\
\hline "La Alicia" & Manuel Morales & En trámite \\
\hline
\end{tabular}

(Figura 6): Estancias de la zona de influencia de "Bajo Caracoles" (1952-1953) ${ }^{21}$

Los boletos de marca sirven como indicadores de un primer acercamiento sobre la actividad ganadera de la región. No obstante ello, debemos señalar la existencia de un mundo aún más amplio, cuya informalidad no deja registros, y que eran parte de la zona de influencia del hotel tales como los peones en permanente movilidad, viajeros, funcionarios del territorio y carreros. Esta importancia en una escala regional permite comprender por qué "Bajo Caracoles" se constituye como localidad, a diferencia de los hoteles "Riera", "Las Horquetas" y "Olnie", situándose allí -en tiempo del TNSC- el Juzgado de Paz a cargo del juez Amador Álvarez Muñiz.

\section{Transportes y comunicaciones:}

Durante la colonización efectiva del NO de Santa Cruz (hacia mediados de la década de 1920) las comunicaciones y el transporte fueron dos grandes dificultades con las cuales debieron convivir los habitantes de la región.

21 Fondo de Gobernación (1884-1955). Archivo Histórico Provincial. Expedientes: 0515/1952; 0516/1952; 0517/1952; 0519/1952; 0521/1952; 0525/1952; 0529/1952; 0532/1952 ; 0533/1952 ; 0535/1952; 0645/1952; 0646/1952;0647/1952;0648/1952;0650/1952;0652/1952;0654/1952;0655/1952;0666/1952;0670/1952; 0801/1952; 0804/1952; 1108/1953; 1322/1953. 
La red caminera se fue constituyendo de forma fragmentaria y tardía con respecto a la ocupación del espacio, siendo una tarea emprendida de forma decidida tras la constitución formal de la provincia de Santa Cruz (1955). Hasta la segunda mitad del siglo XX, las principales vías de circulación de bienes y personas se realizaba en pasos improvisados, muchos de los cuales, según es la idea generalizada, eran coincidentes con antiguas vías de circulación de las comunidades indígenas (García, 2000) ${ }^{22}$. Hasta la introducción masiva del automóvil, en mediados de la década de 1930, el transporte de bienes y personas se realizaba mediante caravanas de carros, chatas y carretas (Figura 7).

\begin{tabular}{|c|c|c|}
\hline Carro & Chata & Carreta \\
\hline $\begin{array}{l}\text { "Un gran vehículo, } \\
\text { construido enteramente de } \\
\text { madera ensamblada con } \\
\text { bulones de hierro y provisto } \\
\text { de un par de enormes ruedas } \\
\text { enllantadas y dos gruesas } \\
\text { varas que iban asentados } \\
\text { sobre el eje del hierro" }\end{array}$ & $\begin{array}{l}\text { "Era un carromato. Algo más } \\
\text { grande y perfeccionado que } \\
\text { el carro, pues era más largo y } \\
\text { tenía cuatro ruedas". }\end{array}$ & $\begin{array}{l}\text { "De menor envergadura que } \\
\text { el carro, tenía tablazón o piso } \\
\text { de madera, a veces con caja } \\
\text { muy sencilla asentada sobre } \\
\text { el eje. Sus ruedas eran más } \\
\text { pequeñas, y las varas eran } \\
\text { reemplazadas por un grueso y } \\
\text { largo tirante al que se } \\
\text { aseguraban los yugos, y se } \\
\text { uncían los bueyes" }\end{array}$ \\
\hline
\end{tabular}

(Figura 7) Contraste entre rodados según Llaras Sametiera (1987) en la Revista Patagonia No38 (P.50)

Las huellas de los carros, chatas y carretas se encuentran dispersas por toda la provincia (Figura 8). Eran los únicos medios óptimos para atravesar las improvisadas rutas. Pese a su uso frecuente, continuaban siendo una traba para el desenvolvimiento económico de la región (un viaje de ida y vuelta desde la cordillera a la costa podía durar entre 30 y 45 días). ${ }^{23}$

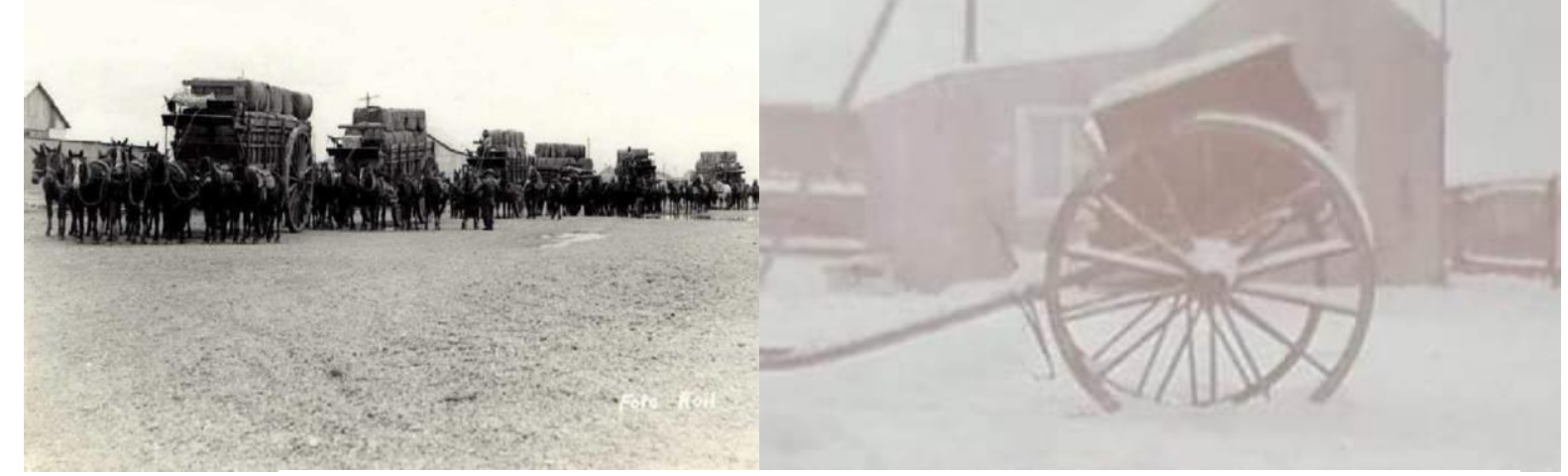

(Figura 8) Transporte de lana en grandes caravanas (1934) Foto Walter Roil, Río Gallegos (Izquierda) Carro bajo nieve zona Río Gallegos y Lago Argentino (S/F). Foto Sonia Ockershausen (Derecha)

\footnotetext{
22 Para profundizar acerca de las vías de circulación de las comunidades indígenas en la región lindante al área del río Santa Cruz consultar: Gilio, B (2017) Modelos de caminos óptimos entre la cuenca superior y media del río Santa Cruz en Arqueología 24(3) Dossier septiembre-diciembre: (143-164).

23 Los prolongados viajes de carros, carretas y chatas han inspirado la producción de literatura acerca de las aventuras de los denominados "carreros", encargados del desarrollo de los transportes en el territorio. Abeijón, A. (1994) “Memoria de un carrero patagónico”. Buenos Aires: Galerna.
} 
Con respecto a la red caminera, según García (2000) hacia 1916 solamente se contaba con la traza de caminos desde Río Gallegos a Lago Argentino, de Última Esperanza (Chile) a La Esperanza y de Puerto Santa Cruz a Lago Argentino. La movilidad de mercaderías y personas por el resto del territorio se realizaba mediante las improvisadas rutas que se han descripto anteriormente ${ }^{24}$.

En el área de estudio (Figura 1) es posible identificar una dinámica compleja en cuanto a las vías de circulación de uso frecuente. La propia $\mathrm{RNN}^{\circ} 40$ fue proyectada por la cordillera (donde están los principales establecimientos productivos) y no por la meseta o bordeándola, que es donde la podemos encontrar actualmente.

Al norte del río Santa Cruz existió un camino principal que unía al sector lindante al Lago Viedma con Paso Ibáñez (actual Cmte. Luis Piedra Buena). Este camino entre la costa atlántica y la cordillera es señalado como el óptimo por el agrimensor Molinari en sus expediciones del año 1903. Con modificaciones, el trazo se corresponde con la actual Ruta Nacional No288. Alberto M. De Agostini $(1945)^{25}$ describe su traslado desde Puerto Santa Cruz al Monte Fitz Roy por este mismo trayecto (Figura 9). Versiones locales indican que las estancias en la zona de influencia del Lago Viedma acudían a Puerto Santa Cruz por razones de viabilidad y distancia (Halvorsen, 2009). Hasta 1918, los fardos de lana se conducían en galetas desde los puertos del Territorio Nacional de Santa Cruz hacia Punta Arenas, sede de los negocios de la Patagonia Austral (Figura 8). A partir de ese año, las producciones nacionales se centralizarán en Buenos Aires, con motivo de la modificación de la política fiscal y la aplicación efectiva de impuesto de aduana.

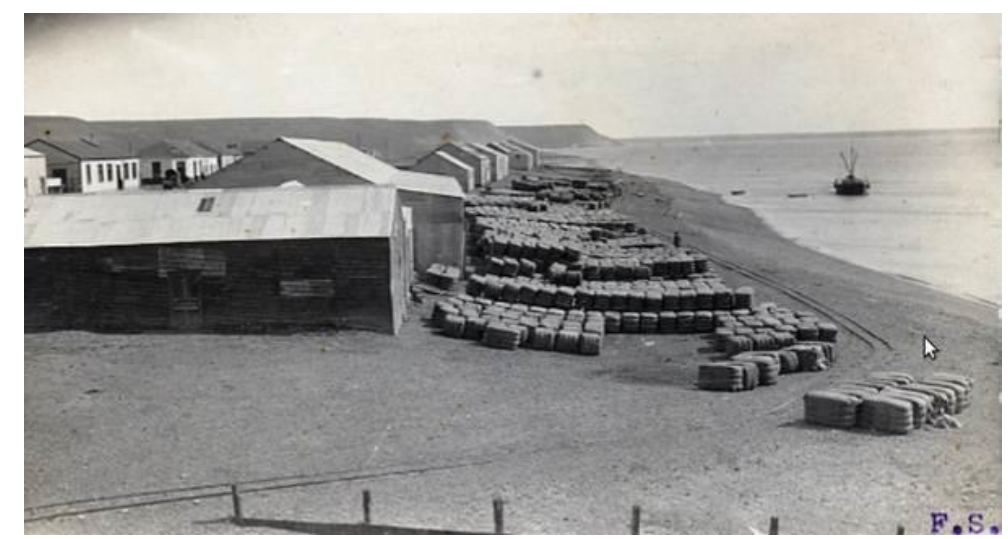

(Figura 8) Fardos de lana esperando ser transportados, Puerto Santa Cruz. Foto: Santesteban. Colección: Marco Luis Marinkovic

Los hoteles de campo antes descriptos, situados al norte del Lago Viedma, muestran otro patrón de circulación de bienes cuyo centro de referencia será la localidad de Puerto San

24 Los pasos improvisados, muchas veces sujetos a los caprichos de los propietarios, con constantes cierres y dificultades, fueron motivo de controversia entre los pobladores. Serán los particulares quienes realizarán esfuerzos significativos a los fines de garantizar el tránsito eficaz de sus bienes y la accesibilidad a sus propiedades. No resulta casual la acción de la Sociedad Rural de Puerto San Julián, que en 1932 solicitará la autorización para construir un camino hacia la cordillera con paso por la localidad.

25 En la crónica del viajero (1945) se destaca la combinación de carros y automóviles y su paso por boliches y estancias de la región, especialmente por la Estancia "Julia" y "La Alicia", donde quedará deslumbrado por la actividad agrícola desarrollada en la primera, perteneciente al vasto dominio de la Sociedad Anónima Importadora y Exportadora. 
Julián. Este hecho nos muestra la complejidad y variabilidad de rutas de circulación de la lana en el área de estudio (Figura 9).

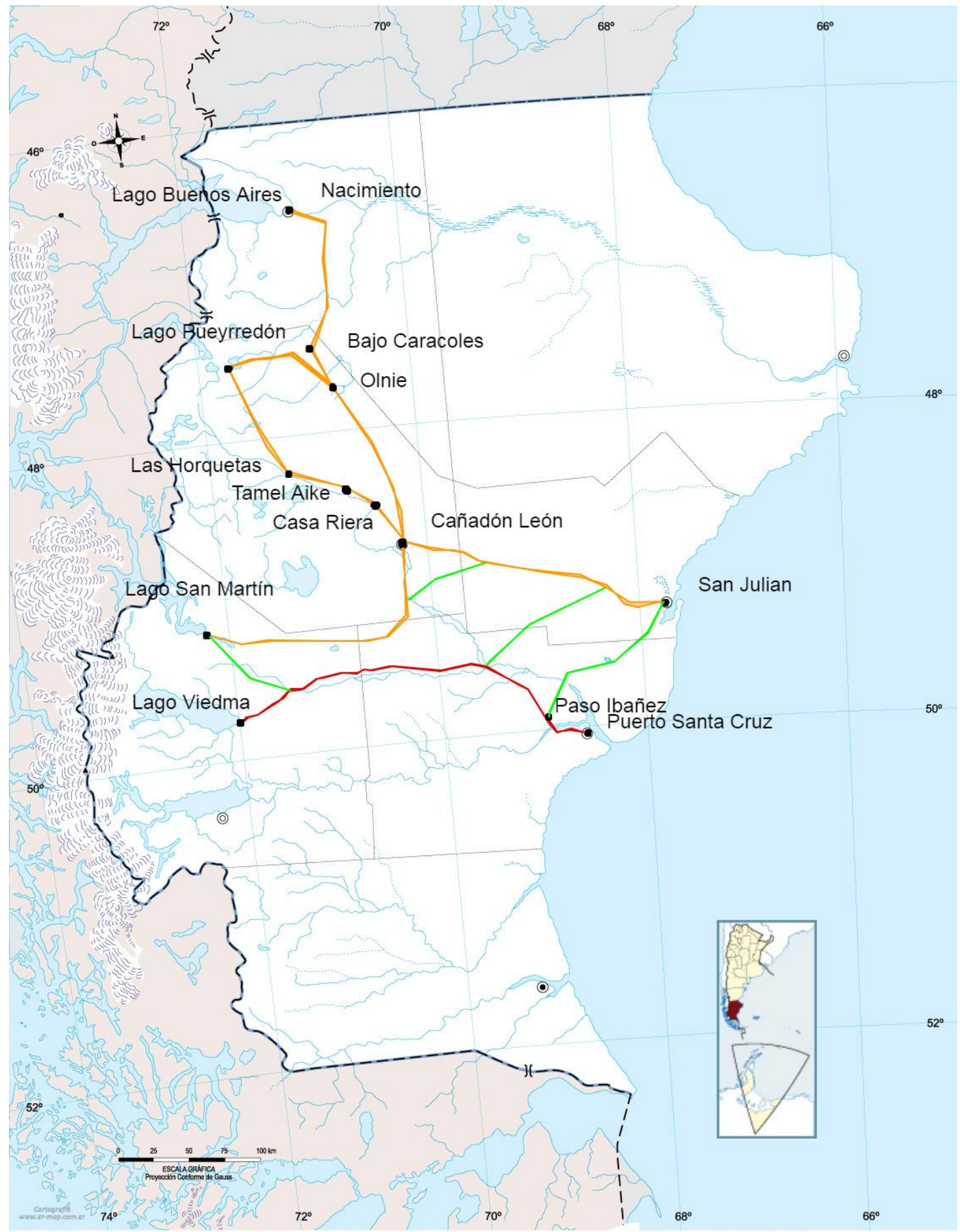

Ruta principal entre Santa Cruz y Lago Viedma según Molinari (1903)

Ruta principal entre Santa Cruz y la cordilerra según Barberia

Conexiones entre las rutas principales (Informes de inspecciones de tierra)

(Figura 9) Posibles trayectorias de las caravanas de lana en el área de estudio. Elaboración propia según Barbería (1995) Inspecciones de Tierra (1900-1930) y Molinari (1903)

Transcribimos aquí un informe correspondiente a la Inspección de Tierras de la Colonia General Paz, ordenada por la Dirección de Tierras y Colonias que resulta ilustrativa del patrón de circulación de bienes en la región: 
"Caminos: El único camino que existe es el camino general de San Julián a la Cordillera que atraviesa por el ángulo N.O del Lote 11 Fracción C y sigue por la parte Norte del 15 fracción $D$, en malas condiciones en algunos lugares y con muy malos pasos en los ríos Belgrano, Lista, Chico y otros por falta de puentes en todos ellos. Distancia al punto de embarque: San Julián es el Puerto de embarque y dista a unas 85 leguas, más o menos. Fletes: Se paga de 0.20 a 0.22 centavos el kilogramo según época y estado de los caminos "26.

Al iniciarse 1930, en el área de estudio se encuentra construido un camino que se extendía entre Puerto San Julián y Cañadón León, el mismo pasaba por el cañadón llamado de la Compañía (García, 2000). Cañadón León se constituirá como un paso obligado de los carros, chatas y carretas que transportaban lanas y cueros hacia Puerto San Julián. Herman Reichert, en un testimonio recuperado por Cerrato (2000) cuenta que solamente por la zona "operaban entre 80 y 90 carretones tirados por caballos". Una estimación más precisa brinda el siguiente registro de transportes de Cañadón León (1926).

\begin{tabular}{|l|l|}
\hline Tipo & Total \\
\hline Automóviles livianos & 14 \\
\hline Automóviles pesados & 2 \\
\hline Camiones livianos & 6 \\
\hline Camiones pesados & 9 \\
\hline Carros de 2 ruedas & 2 \\
\hline Carros de 4 ruedas & 15 \\
\hline Carretas de 2 ruedas & 11 \\
\hline TOTAL: & 59 \\
\hline
\end{tabular}

(Figura 10) Registro de automóviles Cañadón León (1926) en Cerrato (2000)

Hacia la década de 1920 la producción anual de lana del Departamento de Río Chico era de un millón de kilogramos, lo que implicaba, según las estimaciones de Cerrato (2000) la salida de más de 150 carretones durante el tiempo de esquila. Saúl Cuasmicú (1935), en un informe ordenado por la gobernación de Juan Manuel Gregores, estima en un total de 1633 los medios de transporte de tracción de sangre en todo el TNSC (Figura 11):

\begin{tabular}{|c|c|c|}
\hline Carros de 2 ruedas & 372 & \multirow{2}{*}{629} \\
\cline { 1 - 2 } Carros de 4 ruedas & 247 & \multirow{2}{*}{132} \\
\cline { 1 - 2 } Carruajes de 2 ruedas & 106 & \multirow{2}{*}{310} \\
\hline Carruajes de 4 ruedas & 26 & 141 \\
\hline Carretas de 2 ruedas & 252 & 273 \\
\cline { 1 - 2 } Carretas de 4 ruedas & 58 & 146 \\
\hline \multicolumn{2}{|c|}{ Jardineras de reparto } & 1633 \\
\hline Bicicletas & TOTAL & \\
\hline
\end{tabular}

(Figura 11) Estadísticas sobre medios de transporte realizadas por Saúl Cuasmicu (1935) 
Al respecto, vale señalar que el objeto del mismo fue demostrar la prevalencia de los transportes de tracción mecánica, que Cuasmicú estima en un total 2620 vehículos en todo el Territorio entre automóviles, camiones, tractores, motocicletas y vagonetas de remolque por encima de los transportes a tracción de sangre. Más allá de este número mayor, es de destacar la importancia que aún conservaban estos últimos en momentos de sustitución de una tecnología por otra.

Los carros continuaron en funcionamiento por varias décadas. Así, en 1954, aún existían reclamos de pobladores de Cañadón León solicitando que se confeccionara una tranquera que facilite el paso de carros y ganado en la zona ${ }^{27}$. La subsistencia de esta tecnología por varias décadas, sin embargo, no podrá revertir su tendencia a la desaparición ya señalada por Cuasmicú $(1935)^{28}$. En 1939, el uso de los automotores ya es generalizado y desaparecerán lentamente las caravanas. Esto implicará la disminución de las personas en tránsito, lo que se traduce en el cierre lento de hoteles y boliches a lo largo del camino (Cerrato, 2000).

\section{Caracterización de los hoteles como recursos culturales:}

De acuerdo con la metodología utilizada (Ferrari et al 2013 y Navarro et al 2013), los hoteles de campo pueden ser caracterizados como recursos culturales, pertenecientes a la categoría "Museos y manifestaciones culturales históricas" y al tipo "lugar histórico". Estos recursos presentan como tendencia ser recursos administrados actualmente por privados, contar con accesibilidad física a la vera de la Ruta Nacional $\mathrm{N}^{\mathrm{o}} 40$ y formar parte de un corredor dotado con una demanda turística de escala internacional.

El empleo de antiguos hoteles de campo como recursos turísticos cuenta con antecedentes en la región y particularmente sobre la actual RN40. El Hotel Bella Vista y el Hotel La Leona son dos ejemplos de ello, siendo ambos recursos reconocidos como patrimonio cultural de la provincia de Santa Cruz.

El Hotel La Leona, cuenta con un edificio que conservando su fachada original ha sido adaptado para brindar confort y servicios a los turistas del área cordillerana. Este hotel, más allá de su ubicación estratégica, cuenta con una decoración y señalización que en todo tiempo remite a su importancia como sitio histórico y manifestación cultural, contando con vidrieras que exponen colecciones con restos fósiles, arqueológicos e históricos, además de una decoración con cartografía y fotos históricas, muchas de las cuales remiten a célebres viajeros que transitaron la zona. Este sitio que fuera reconocido como patrimonio cultural provincial ha sido objeto de relevamiento y estudio por parte del PI 29/A332-1, que elaboró una propuesta de circuito turístico integrando el hotel a los atractivos turísticos cercanos al sitio (Vidal, Navarro y Espinosa 2017). El Hotel Bella Vista, situado al sur del mismo corredor de la RN 40, ha sido declarado bien patrimonial por la Secretaría de Estado de Cultura de Santa Cruz y es actualmente un sitio de pesca deportiva que alberga fundamentalmente pescadores.

\section{Jerarquización de los hoteles como recursos culturales:}

En una segunda instancia de trabajo, se procedió a la jerarquización de los hoteles estudiados, determinándose un puntaje final para cada uno de ellos tras un relevamiento del estado actual de cada uno de los recursos y su entorno.

\footnotetext{
27 Fondo de Gobernación (1884-1955). Archivo Histórico Provincial. Expediente: 8096/1954.

28 El año 1935 marca un antes y después en el desarrollo de los transportes de la región. En este año se registra, en la localidad de Cañadón León, la instalación de un surtidor de expendio de nafta 'YPF' y de un surtidor de nafta 'Astra'” en el negocio de Ramos Generales '’Brunet Hnos'. Op. cit. Expediente: 3836/1935.
} 


\begin{tabular}{|c|c|}
\hline Hotel de campo & $\begin{array}{c}\text { Puntaje total } \\
\text { Obtenido }\end{array}$ \\
\hline Hotel Bajo Caracoles & 35 puntos \\
\hline Hotel Las Horquetas & 32 puntos \\
\hline Ex Hotel Olnie & 24 puntos \\
\hline Ex Hotel Riera & 22 puntos \\
\hline
\end{tabular}

(Figura 12). Jerarquización de cada hotel según la sumatoria de todos sus atributos.

Las diferencias en cuanto a jerarquía de los sitios está dada por las distintas ponderaciones en algunas variables que resultan de relevancia para desarrollar una posible actividad turística ligada al recurso. En este sentido, los valores nominales obtenidos de las variables "estado actual de la conservación del recurso", "estado actual de la conservación del entorno", "servicios e instalaciones" $y$ "explotación actual" resultaron los principales rasgos diferenciales entre los distintos hoteles.

Los resultados de la evaluación de los hoteles nos muestran como tendencia dos grupos bien diferenciados de recursos:

Los hoteles que presentan grandes alteraciones y que actualmente no están en funcionamiento (Hotel Olnie, Hotel Riera) que han dado como resultado su abandono y falta de mantenimiento (Hotel Olnie) o el desarmado de su estructura edilicia y su posterior cercado (Hotel Riera). Estos recursos no son utilizados actualmente y no se encuentran equipados con ningún servicio. Las principales valoraciones de ambos hoteles (en torno a los 20 puntos) se corresponden con su ubicación estratégica, su accesibilidad sobre la Ruta Nacional $\mathrm{N}^{\circ} 40$, su presencia en un corredor internacional y sus peculiaridades históricas, siendo en general negativos los resultados de sus evaluaciones acerca de su vulnerabilidad, estado actual, conservación y servicios (Tabla 2).

Los hoteles que presentan algunas alteraciones edilicias o en su entorno y que se encuentran actualmente en funcionamiento (Hotel Las Horquetas, Hotel Bajo Caracoles) que han resultado con buenas valoraciones (por encima de los 30 puntos) por encontrarse dotados de servicios básicos para la atención de los viajeros y presentar un buen estado de conservación de su fachada histórica, con algunas ampliaciones dadas para brindar un mejor servicio.

\begin{tabular}{|c|c|c|c|c|}
\hline Hotel & $\begin{array}{l}\text { Estado actual } \\
\text { del recurso }\end{array}$ & $\begin{array}{l}\text { Estado actual } \\
\text { del entorno }\end{array}$ & $\begin{array}{c}\text { Servicios e } \\
\text { instalaciones }\end{array}$ & $\begin{array}{l}\text { Explotación del } \\
\text { recurso }\end{array}$ \\
\hline $\begin{array}{l}\text { Hotel Riera } \\
\text { (7 puntos) }\end{array}$ & $\begin{array}{l}\text { Muy alterado } \\
\text { (1 punto) }\end{array}$ & $\begin{array}{c}\text { Bien } \\
\text { conservado (4 } \\
\text { puntos) }\end{array}$ & $\begin{array}{c}\text { No presta } \\
\text { servicios ni } \\
\text { instalaciones } \\
\text { (1 punto) }\end{array}$ & $\begin{array}{c}\text { Sin explotación } \\
\text { actual } \\
\text { (1 punto })\end{array}$ \\
\hline $\begin{array}{l}\text { Hotel Las } \\
\text { Horquetas } \\
\text { (16 puntos) }\end{array}$ & $\begin{array}{c}\text { Presenta algunas } \\
\text { alteraciones } \\
\text { (4 puntos) }\end{array}$ & $\begin{array}{l}\text { Entorno bien } \\
\text { conservado } \\
\text { (5 puntos) }\end{array}$ & $\begin{array}{l}\text { Presenta } \\
\text { servicios } \\
\text { mínimos } \\
(3 \text { puntos }) \\
\end{array}$ & $\begin{array}{l}\text { Explotado } \\
\text { (4 puntos) }\end{array}$ \\
\hline $\begin{array}{l}\text { Hotel Olnie } \\
\text { (7 puntos) }\end{array}$ & $\begin{array}{l}\text { Muy alterado } \\
\text { (1 punto) }\end{array}$ & $\begin{array}{c}\text { Bien } \\
\text { conservado (4 } \\
\text { puntos) }\end{array}$ & $\begin{array}{c}\text { No presta } \\
\text { servicios ni } \\
\text { instalaciones } \\
(1 \text { punto })\end{array}$ & $\begin{array}{c}\text { Sin explotación } \\
\text { actual } \\
(1 \text { punto })\end{array}$ \\
\hline $\begin{array}{l}\text { Hotel Bajo } \\
\text { Caracoles } \\
\text { (14 puntos) }\end{array}$ & $\begin{array}{l}\text { Presenta algunas } \\
\text { alternaciones } \\
\text { (4 puntos) }\end{array}$ & $\begin{array}{l}\text { Entorno } \\
\text { modificado } \\
\text { (3 puntos) }\end{array}$ & $\begin{array}{c}\text { Existencia de } \\
\text { servicios básicos } \\
(4 \text { puntos })\end{array}$ & $\begin{array}{l}\text { Explotado } \\
\text { (4puntos) }\end{array}$ \\
\hline
\end{tabular}

(Figura 13). Caracterización y puntaje de los Hoteles sobre rasgos diferenciales 
Ambos recursos culturales encuentran en la actualidad una explotación económica ligada al abastecimiento de los viajeros que transitan la Ruta Nacional No40 y no en su carácter de sitio histórico y/o manifestación cultural, cumpliendo funciones similares a las de su época de apertura con modificaciones en cuanto a las características de los usuarios y de sus medios tecnológicos (antes principalmente pobladores rurales transportados en caballos y caravanas de chatas, carros y carretas, hoy principalmente turistas transportados en automóviles).

\section{Discusión}

Como se ha visto, el área de estudio presenta hacia fines de la década de 1920 e inicios de la década de 1930 un establecimiento incipiente de negocios comerciales y establecimientos productivos. Estos se consolidarán de forma definitiva durante la década de 1950. Durante este largo trayecto histórico se conformarán las primeras unidades políticas en la región, denominadas Comisiones de Fomento que, orientadas por fines prácticos, fueron las encargadas de buscar soluciones a los principales problemas que aquejaron a los pobladores de la región, tales como las referidas al desarrollo económico y comercial, el trazo de caminos comunales, el establecimiento de un eficiente servicio de comunicaciones y la atención primaria de la salud y la educación.

Un origen común compartido, ligado a la expansión de la actividad ovina, y el desarrollo de un comercio regional fue unificando la región del NO del TNSC en ciertos planteamientos comunes. En la década de 1950, junto al proceso de constitución definitiva de la provincia de Santa Cruz (1955), es posible registrar una serie de demandas elevadas por los pobladores de la región a las autoridades locales, provinciales y nacionales, en general ligadas a la atención de necesidades esenciales.

\section{Educación y Salud}

Las dificultades para acceder a la atención de la salud y educación serán un problema primordial para los pobladores de la región. Las asimetrías en los desarrollos provocaron que hacia la década de 1950 sea la localidad de Cañadón León la única localidad con estas prestaciones, contando con una Sala de Primeros Auxilios -atendida por un profesional en el área de la medicina- y con una Escuela Nacional (El Sonido, 1953).

La situación de la educación en la región tendrá tintes dramáticos según evidencian las constantes denuncias presentes en la prensa local, donde el cierre de la Escuela de Lago Posadas a fines de la década de 1940 se constituyó en un tópico frecuente:

"La situación de la escuela-hogar de Lago Posadas, es ya archiconocida a través de comentarios diversos y gestiones múltiples tendientes a su rehabilitación; no obstante ello su estado de abandono continúa sin que se vislumbre una solución más o menos inmediata (...) En toda la vasta zona abundan las familias muy numerosa, cuyos niños se van criando cual plantas silvestres, sin posibilidades de instruir ni de educarse más que a la ruda usanza campera" (El Sonido, 10 de abril de 1953: 3)

Una importante reunión de ganaderos de la región realizada en la localidad de Bajo Caracoles, a inicios del año 1956, a la cual además de la asistencia de numerosos propietarios de la región (Cvjetanovic entre ellos) se encontraban autoridades locales y los señores presidente y secretario de la Sociedad Rural de Puerto San Julián, tomará las siguientes resoluciones acerca del cierre de la escuela:

"Solicitar enérgicamente se ponga término a la vergonzosa situación de analfabetismo imperante en la zona a consecuencia del cierre de la Escuela de Lago Posadas, clausurada hace más de diez años (...) Elevar nota sobre el angustioso problema 
escolar a la Presidencia de la Nación, al ministerio de Educación y a la Gobernación de la Provincia, ofreciendo la amplia colaboración de los pobladores de la zona" (El Sonido, 6 de abril de 1956: 3).

En cuanto a las prestaciones de salud la situación presentaba los mismos tintes:

"Las situaciones de apremio y casos graves de enfermedad se resuelven con frecuencia buscando auxilio en territorio chileno o transportando al enfermo desde Caracoles por vía aérea hacia Comodoro Rivadavia, todo ello con los peligros e inconvenientes que supone el traslado previo". (El Sonido, 10 de abril de 1953: 3)

Hacia la década de 1950, entre los vecinos y pobladores de la zona de Lago Posadas, Río Blanco y Bajo Caracoles se formó una comisión en favor de crear una Sala de Primeros Auxilios. Si bien hacia 1953 los medios de comunicación señalan que no ha pasado de ser un proyecto, la reunión de ganaderos antes citada tomará como resolución solicitar a la Gobernación de Santa Cruz el apoyo a la obra ya encarada por la comisión a fin de habilitar la sala (El Sonido, 1956).

Este hecho refleja que la iniciativa de los pobladores fue determinante en la instalación de los servicios esenciales en la región. En la actualidad, el anhelo de una Sala de Primeros Auxilios es una realidad en la localidad de Bajo Caracoles.

\section{Los reclamos de los ganaderos}

Las fuentes periodísticas en general nos hacen llegar con mayor vigor las demandas preponderantes de esta sociedad rural en conformación: las establecidas por los ganaderos. Además de compartir los reclamos de educación y salud, este sector solicitará a las recién constituidas autoridades provinciales mayor apoyo a la policía, un cupo especial para la exportación de ganado a pie hacia Chile (en las zonas de Posadas, Roballo, Pueyrredón y Caracoles) y denunciará ante la Dirección de Tierras la presencia de "instrusos" (sic) en la zona (El Sonido, 1956).

Las distancias que debieron afrontar para el desarrollo de sus actividades económicas será un aspecto que no ignoran a la hora de presentar sus demandas ante las distintas autoridades. Es así que rechazaran el pago del impuesto del 3\% a las exportaciones establecido por la recién creada provincia argumentando que:

"Debe derogarse la obligatoriedad de la entrega de dicha cuota, máxime en el caso de esta zona, que hallándose a 120 leguas de distancia, deben hacer sus entregas a San Julián" (El Sonido, 6 de abril de 1956: 3).

\section{Un viejo anhelo}

La articulación de intereses entre ganaderos y medios de prensa no sólo se evidencia en torno a las reivindicaciones ligadas a la eximición de impuestos y al reforzamiento de la presencia policial en alrededores de las estancias. Será este mismo instrumento mediante el cual muchos de los pobladores presentarán sus reclamos y proyectos, en este caso ligados al anhelo de construir un polo de desarrollo turístico en la zona lindante al Lago Pueyrredón, anhelo que es anterior a la constitución de la provincia:

"El lugar es espléndido, un rincón realmente privilegiado por la naturaleza, ideal para el turismo y excursiones para pasar una temporada de descanso, pero, lógicamente, para ello haría falta un buen hotel con comodidades adecuadas, dotado de capacidad para alojar un buen número de personas (...) para ello es fundamental una garantía de estabilidad y 
seguridad, factor del cual se carece hasta ahora (...) como un acto de justicia, Tierras debería contemplar y resolver esta situación”. (El Sonido, 10 de abril de 1953: 3)

Las palabras del columnista del periódico apuntan contra los funcionarios de la Dirección de Tierras (dependiente del Ministerio del Interior) en vistas de una demanda regional establecida por los ocupantes de hecho en la zona que reclamaran la adjudicación de territorios en venta a los fines de poner fin a la situación de inseguridad de sus ocupaciones. Este reclamo, iniciado durante la segunda presidencia del peronismo, se concretará tras años de gestión en 1957 en un panorama político completamente distinto y con una recién constituida provincia de Santa Cruz. Como ya se ha dicho, Nicolas Cvjetanovic, de "El Olnie" y Antonio Martínez y Mauro Martínez de "Riera", serán algunos de los tantos beneficiarios de esta modificación en cuanto a la política de concesión de tierras.

\section{CONCLUSIONES}

En este trabajo, a través del análisis trayectoria histórica de los hoteles "Riera", "Las Horquetas", "Olnie" y "Bajo Caracoles" y del particular desarrollo de los transportes de lana de tracción a sangre durante el periodo de estudio, se ha intentado describir algunos rasgos generales acerca de la colonización del NO del TNSC. Se ha demostrado la pertinencia de asimilar el surgimiento de estos hoteles a la actividad de transporte de la producción ovina, siendo los hoteles espacios de acopio de frutos del país, establecimientos ganaderos o espacios de apoyo en zonas de influencia con gran presencia ovina.

Se ha demostrado que la distribución de la tierra en la región aún no ha sido abordada de forma sistemática por la historiografía, existiendo antecedentes (Barbería, 1995) que han caracterizado a las colonias del NO como regiones marginales y con escasos colonos hasta la década de 1920. Al respecto este trabajo ha mostrado que la región posee un incipiente establecimiento de locales productivos y comerciales hacia fines de la década de 1920 y durante la década de 1930. Este desarrollo se consolidará durante la segunda mitad de la década de 1950, época en la cual muchos de los ocupantes de hecho de estos espacios lograran acceder a la propiedad efectiva de la tierra a través de su adjudicación en venta. Este proceso será paralelo a la constitución de Santa Cruz como provincia y al desarrollo de crecientes demandas por parte de los pobladores y ganaderos en aspectos ligados a necesidades esenciales y reivindicaciones económicas, educativas y de salud.

Los hoteles de campo aquí descriptos nos muestran que las distancias transitadas por las caravanas de lanas no fueron desoladoras. Existió un mundo rural poblado, "lleno de gente", con una intensa actividad económica y de exportación cuyo centro de referencia será la localidad de Puerto San Julián. Estos antiguos sitios de acopio, al menos los situados a la vera de la actual Ruta Nacional $N^{\circ} 40$, se adaptaron a los cambios en tecnologías de transporte durante la década de 1950. "Las Horquetas" y "Bajo Caracoles" resisten el paso de los años, "Olnie" y "Riera" son solo vestigios del pasado. Todos ellos presentan una larga historia que resta escribirse.

Al igual que se ha demostrado en relevamientos previos de recursos culturales y hoteles de campo (Vidal, Navarro y Espinosa 2017), se considera que la realización de un recorrido cultural por la Ruta Nacional $\mathrm{N}^{\circ} 40$ presenta grandes potencialidades y factibilidad, existiendo compatibilidad y complementariedad con los actuales recursos turísticos del corredor Gobernador Gregores-Perito Moreno. La articulación de estas propuestas, con un reconocimiento de los hoteles como patrimonio cultural protegido legalmente, su correcta señalización y articulación conjunta con los propietarios privados puede resultar en propuestas turísticas exitosas y sustentables como demuestra el Hotel La Leona, recurso turístico consolidado al sur del corredor aquí relevado. 


\section{AGRADECIMIENTOS}

A Milagros Pierini, Pablo Beecher, Roberto Molinari, Rafael Goñi, Francisco Marinkovic, Marcos Marinkovic y Osvaldo Garate por haber facilitado información y documentación utilizada en este trabajo. Al personal del Archivo Histórico Provincial. A los compañeros de equipo durante las tareas de relevamiento. Al Consejo Interuniversitario Nacional.

\section{ANEXO}

\section{Fuentes inéditas:}

Informes de Inspección de Tierra (1900-1930). Libros Copiadores varios. Archivo Histórico Provincial de la Provincia de Santa Cruz.

Obra de Gobierno J. M Gregores. Libros Copiadores varios. Archivo Histórico Provincial de la Provincia de Santa Cruz.

Fondo Gobernación de Santa Cruz (1884-1955). Expedientes varios. Archivo Histórico Provincial de la Provincia de Santa Cruz.

\section{Fuentes editas:}

Codificación del registro de marcas expedidas en el Territorio Nacional de Santa Cruz, épocas 1893 a Diciembre 1937 (1937). Gobernación de Santa Cruz. Oficina de marcas. Edición oficial. Rio Gallegos

\section{Fuentes periodísticas:}

Semanario El Sonido (1950-1957). Puerto San Julián.

\section{BIBLIOGRAFÍA}

AgOSTINI, A. M. (1945). Andes Patagónicos: Viaje de exploración a la cordillera Patagónica Austral. Buenos Aires.

ALMENDRAS, A., FERRARI, S. y DIEZ, P. (2016). Evaluación del recurso aves como base para el desarrollo del turismo ornitológico en el Corredor RN40 tramo Río Turbio Gobernador Gregores (Santa Cruz). Revista de Informes Científicos Técnicos de la UNPA. Vol. 8 Núm.2: 91-112

BARBERÍA, E. M. (1995). Los dueños de la tierra en la Patagonia Austral, 1880-1920. Universidad Nacional de la Patagonia Austral, Santa Cruz

BAYER, O. (1986). La Patagonia Rebelde. Hyspamérica Ediciones Argentina, Buenos Aires ( $1^{\circ}$ edición: 1980$)$.

CERRATO, J. C. (2000). El Gran Libro de la Provincia de Santa Cruz. Alfa Milenio Ediciones. Página 647.

CORREA FALCON, E y KLAPPENBACH, L (1924) La Patagonia Argentina. Estudio gráfico y documental del Territorio Nacional de Santa Cruz. Impreso en los talleres G. Kraft, Buenos Aires

CUASMICÚ, S. (1935). Somera historia de su conquista por la colonización, estado actual, descripción física, histórica, ganadera, industrial, comercial y social; Santa Cruz: Santa Cruz. Páginas 141 a 158. 
FERRARI, S., PASTOR, G., ALBRIEU, C., y ALBRIEU, M. L. (2013). Recomendaciones para la explotación turística sustentable de la Ruta N40 vinculando áreas protegidas en la Patagonia Austral Argentina. Memorias de la IX Convención Internacional sobre Medio Ambiente y Desarrollo. VIII Congreso de Áreas Protegidas. La Habana, Cuba. pp. 1508- 1526. Recuperado de http://www.cubambiente.com/es/general13. Consultado el 23/10/2019.

FERRARI, S., ALBRIEU, C, NAVARRO, V., MAZZONI, E, ESPINOSA, S., BIOTT, J. y ALMENDRAS, A. (2015). Inventario y jerarquización de atractivos y recursos naturales/culturales en el tramo Austral de la RN40 (Santa Cruz). VII Simposio Internacional y XII Jornadas Nacionales de Investigación - Acción en Turismo CONDET Congreso Internacional de Turismo - ANET. Universidad del Comahue.

FRADKIN, R. (1993). La historia agraria del Rio de la Plata colonial. Los establecimientos productivos (I). Centro Editor de América Latina SA.

GARCIA, A. N. (2000). El Gran Libro de la Provincia de Santa Cruz. Alfa Milenio Ediciones. Página 584.

GELMAN, J, (2017). De la historia agraria a la historia de las desigualdades. Anuario IEHS Volumen 32-2.

HALVORSEN, P. (2009). La Leona, Historias de balsas, boliches y enredos. Patagonia Sur Libros. Argentina.

MARTINIC, M. (2005). La Hotelería en el Antiguo Magallanes (1870-1950). Magallania, (Chile) Vol. 33(1):5-24.

NAVARRO, V., BIOTT, J. M., y ALMENDRAS, A. (2013). Identificación de atractivos para el turismo y la recreación en el tramo Cabo Vírgenes-Río Gallegos de la RN 40 (Santa Cruz). En Navarro, V., y Ferrari, S. (Comps.), Turismo y recursos naturales: los recursos naturales como base del desarrollo turístico local, importancia de la conservación y la gestión para la sustentabilidad. Santa Cruz, Argentina, Editora Universidad Nacional de la Patagonia Austral, pp. 147-182.

PIERINI, M. y BEECHER, P. (2014). La comunidad española en Santa Cruz 1884 - 1970. Capitulo VII. Argentina 